Article

\title{
Sensitivity of Sentinel-1 Backscatter to Vegetation Dynamics: An Austrian Case Study
}

\author{
Mariette Vreugdenhil ${ }^{1, *} \mathbb{\infty}$, Wolfgang Wagner ${ }^{1}(0)$, Bernhard Bauer-Marschallinger ${ }^{1}(\mathbb{D}$,

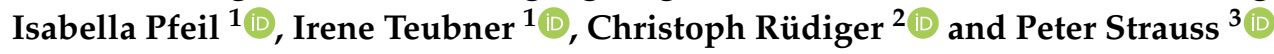 \\ 1 Department of Geodesy and Geoinformation, TU Wien, 1040 Vienna, Austria; \\ wolfgang.wagner@geo.tuwien.ac.at (W.W.); bernhard.bauer-marschallinger@geo.tuwien.ac.at (B.B.-M.); \\ isabella.pfeil@geo.tuwien.ac.at (I.P.); irene.teubner@geo.tuwien.ac.at (I.T.) \\ 2 Department of Civil Engineering, Monash University, 3800 Clayton, Australia; chris.rudiger@monash.edu \\ 3 Institute for Land and Water Management Research (IKT), Federal Agency of Water Management, \\ 3252 Petzenkirchen, Austria; peter.strauss@baw.at \\ * Correspondence: mariette.vreugdenhil@geo.tuwien.ac.at; Tel.: +43-1-55801-12260
}

Received: 20 July 2018; Accepted: 29 August 2018; Published: 1 September 2018

\begin{abstract}
Crop monitoring is of great importance for e.g., yield prediction and increasing water use efficiency. The Copernicus Sentinel-1 mission operated by the European Space Agency provides the opportunity to monitor Earth's surface using radar at high spatial and temporal resolution. Sentinel-1's Synthetic Aperture Radar provides co- and cross-polarized backscatter, enabling the calculation of microwave indices. In this study, we assess the potential of Sentinel-1 VV and VH backscatter and their ratio $\mathrm{VH} / \mathrm{VV}$, the cross ratio (CR), to monitor crop conditions. A quantitative assessment is provided based on in situ reference data of vegetation variables for different crops under varying meteorological conditions. Vegetation Water Content (VWC), biomass, Leaf Area Index (LAI) and height are measured in situ for oilseed-rape, corn and winter cereals at different fields during two growing seasons. To quantify the sensitivity of backscatter and microwave indices to vegetation dynamics, linear and exponential models and machine learning methods have been applied to the Sentinel-1 data and in situ measurements. Using an exponential model, the CR can account for $87 \%$ and $63 \%$ of the variability in VWC for corn and winter cereals. In oilseed-rape, the coefficient of determination $\left(R^{2}\right)$ is lower $\left(R^{2}=0.34\right)$ due to the large difference in VWC between the two growing seasons and changes in vegetation structure that affect backscatter. Findings from the Random Forest analysis, which uses backscatter, microwave indices and soil moisture as input variables, show that $\mathrm{CR}$ is by and large the most important variable to estimate VWC. This study demonstrates, based on a quantitative analysis, the large potential of microwave indices for vegetation monitoring of VWC and phenology.
\end{abstract}

Keywords: Sentinel-1; vegetation water content; microwave indices; crops

\section{Introduction}

With increasing stress on food supply due to the growing world population and changing climate [1,2], vegetation monitoring and risk mitigation are essential for ensuring food security. By closely tracking crop conditions, agricultural droughts and subsequent crop losses could be better dealt with and yield predictions can be improved. In addition, crop monitoring can assist in more sustainable land management and reducing the use of pesticides and fertilizers.

Spaceborne microwave remote sensing provides the means to monitor vegetation and soil conditions on a range of scales. Synthetic Aperture Radars (SAR) provide observations at a high spatial resolution in the order of tens of meters, which can be used for agricultural crop monitoring [3]. 
However, until recently, high resolution SAR observations were not frequent enough to be used to monitor vegetation dynamics in a way to be useful to farmers. With the launch of the European Space Agency (ESA) Copernicus Sentinel-1 satellite series, backscatter observations are available at an unprecedented temporal and spatial resolution, with a revisit time of 1.5-4 days over Europe and a spatial resolution of $20 \mathrm{~m}$. Since microwaves are sensitive to the water content in the soil and vegetation and other variables influencing backscatter, i.e., soil roughness and vegetation structure, the challenge in microwave remote sensing is to retrieve the vegetation signal.

At a large scale, many studies have demonstrated the use of microwave sensors for vegetation monitoring, like EUMETSATs Metop Advanced SCATterometers (ASCAT), JAXAs Advanced Microwave Scanning Radiometer 2 (AMSR2), ESAs Soil Moisture Ocean Salinity (SMOS) mission and NASAs Soil Moisture Active Passive (SMAP), [4-11]. The temporal sampling for these products is 1-2 days, but the spatial resolution is relatively coarse with pixels covering tens of kilometres. Often, Vegetation Optical Depth is derived, which is an indicator of the water content in the above ground biomass. At the field scale, many studies have used backscatter directly or indices thereof to find a relation to vegetation dynamics. Ferrazzoli et al. [12] found that HV-polarized backscatter at C-band correlated strongly $\left(R^{2}=0.75\right)$ with crop biomass over colza, wheat and alfalfa, but that saturation occurred in corn, sunflower and sorghum. Paloscia et al. [13] found high correlations between vegetation biomass and HV-backscatter over broad leaf crops such as sunflower. In addition, Macelloni et al. [14] found an increase in VH backscatter with increasing Leaf Area Index (LAI) over rapeseed sites in Italy and Sweden. Ratios of co- and cross-polarized backscatter observations, i.e., the Radar Vegetation Index (RVI) [10,15] and Cross Ratio (CR) [16], were found to distinguish well between vegetation densities and high linear correlations were found to in situ measured Normalized Difference Vegetation Index (NDVI), LAI and Vegetation Water Content (VWC) over different crops [15]. Wiseman et al. [17] compared dry biomass to C-band RADARSAT backscatter for a six-week period in southern Manitoba, Canada. Significant correlations were found for corn, soybean and oilseed-rape, which increased when applying a logarithm to the observations. In addition, radar backscatter was also found to be sensitive to crop structure changes and phenology. This was also found by Mattia et al. [18] and Satalino et al. [19], where backscatter changed drastically with the emergence of heads in wheat. More recently, Veloso et al. [20] compared Sentinel-1 time series to NDVI time series for wheat, oilseed-rape, corn, soybean and sunflower over test sites in France. Good correspondence was found between SAR data and NDVI. Particularly, the VH/VV ratio could be used for monitoring crop growth cycles. A qualitative comparison was performed between VH/VV and in situ measured biomass for barley and corn and showed a good agreement. These studies demonstrate the potential of SAR and especially Sentinel-1 to monitor vegetation dynamics.

The aim of this study is to further quantify the potential of Sentinel-1 backscatter to monitor vegetation dynamics. We assess the sensitivity of Sentinel-1 VH and VV backscatter and ratio thereof to vegetation dynamics by comparing them to in situ measured vegetation variables, such as VWC, LAI, height and biomass. Destructive vegetation samples were taken for two consecutive years, with very different meteorological conditions, during the growing season of winter cereals, corn and oilseed-rape. A linear model, exponential model and random forest machine learning are used to understand the signal and assess the potential of combining microwave indices from Sentinel- 1 to estimate VWC. Testing the use of freely available microwave indices and products in combination with machine learning approaches ensures applicability on a large scale and to ultimately develop predictive models for VWC. The advantage of the presented approach is that no a priori information on vegetation structure is needed, which was often the case in previous studies estimating VWC. This work advances from previous studies by providing for the first time a quantitative performance assessment of Sentinel-1 for monitoring vegetation dynamics over multiple crop types and years. 


\section{Data}

\subsection{Site Description}

The study is performed in the Hydrological Open Air Laboratory (HOAL) [21], which is a 66 hectare large catchment located in Petzenkirchen, Austria $\left(48^{\circ} 9 \mathrm{~N}, 15^{\circ} 9 \mathrm{E}\right)$ and managed by the Austrian Federal Agency of Water Management and TU Wien. Elevation varies between 268 and $323 \mathrm{~m}$ and the average slope is $8 \%$. The main land use in the catchment is agriculture and most common crops are winter wheat and corn. Dominant soil types are Cambisols and Planisols with medium to poor infiltration capacity. Average temperature in the $\mathrm{HOAL}$ is $9.5^{\circ} \mathrm{C}$ and mean annual precipitation is $823 \mathrm{~mm}$ per year. The peak of precipitation is usually in summer.

In 2016 and 2017, samples of vegetation variables were taken every 12 or 24 days during the growing season, coinciding with the same orbit of Sentinel-1. Only during one orbit of Sentinel-1 samples were taken, since the incidence angle is the same for this orbit. The overpass time of Sentinel-1 was at 5:09 a.m. and sampling was done as close to this time as possible. A total of six sampling units (SU) were selected for sampling of vegetation and soil moisture. Different crops were sampled: oilseed-rape, corn and winter cereals barley and wheat. Measurements were taken at random locations within a $20 \mathrm{~m}$ radius from the centre of the SU. The location of the SUs is depicted in Figure 1.

\subsection{In Situ Data}

\subsubsection{Biomass and Vegetation Water Content}

Wet biomass (BM) and VWC are determined by destructive sampling and oven drying of the samples. Samples were separated in stems and leafs, resulting in three VWC measurements, total VWC $\left(V_{W}\right)$, leaf VWC $\left(V_{W C}\right)$ and stem VWC $\left(V_{W}\right)$. Since the croplands are owned by farmers and sampling is frequent, per sampling day a number of plants or rows were cut and $\mathrm{BM}_{\text {and }} \mathrm{VWC}_{t}$ are determined per plant or row. In corn and oilseed-rape, three plants per sampling day were taken. In winter cereal, two or three rows were cut with a total length of 50 centimeters. To acquire an estimate of BM and VWC per $\mathrm{m}^{2}$, the row or plant density on $1 \mathrm{~m}^{2}$ was counted for every croptype and subsequently BM and VWC at $1 \mathrm{~m}^{2}$ were calculated. In the laboratory, samples were separated for stems and leafs and separately weighted before and after oven-drying. Oven-drying was done at $70{ }^{\circ} \mathrm{C}$ for 24 to $48 \mathrm{~h}$ until the dry weight was stable.

\subsubsection{Leaf Area Index}

Leaf Area Index (LAI) is measured using a Licor LAI-2000 Plant Canopy Analyzer (Lincoln, NE, USA). The LAI-2000 measures light intensity with a fish-eye lense in five concentric field of views, with zenith angles of 7, 23, 38, 53 and 68 degrees. For every measurement, one above-canopy and six below-canopy readings are acquired. The ratio between the above- and below-canopy reading is used to calculate gap fraction and subsequently LAI using the built-in software C2000 LI-COR software (Lincoln, NE, USA). For each SU and sampling day, a total of five repeat LAI measurements were taken, which were distributed randomly around the SU centre. The five LAI measurements were then averaged.

\subsubsection{Vegetation Height and Status}

Vegetation height was measured at five locations for every sampling unit and sampling day and averaged. Height was noted in the field. In addition, photographs were taken of the vegetation to document vegetation status, e.g., seeding, stem extension, flowering, heading, harvest and corn growth stages. An overview of vegetation status is given in Table 1. 


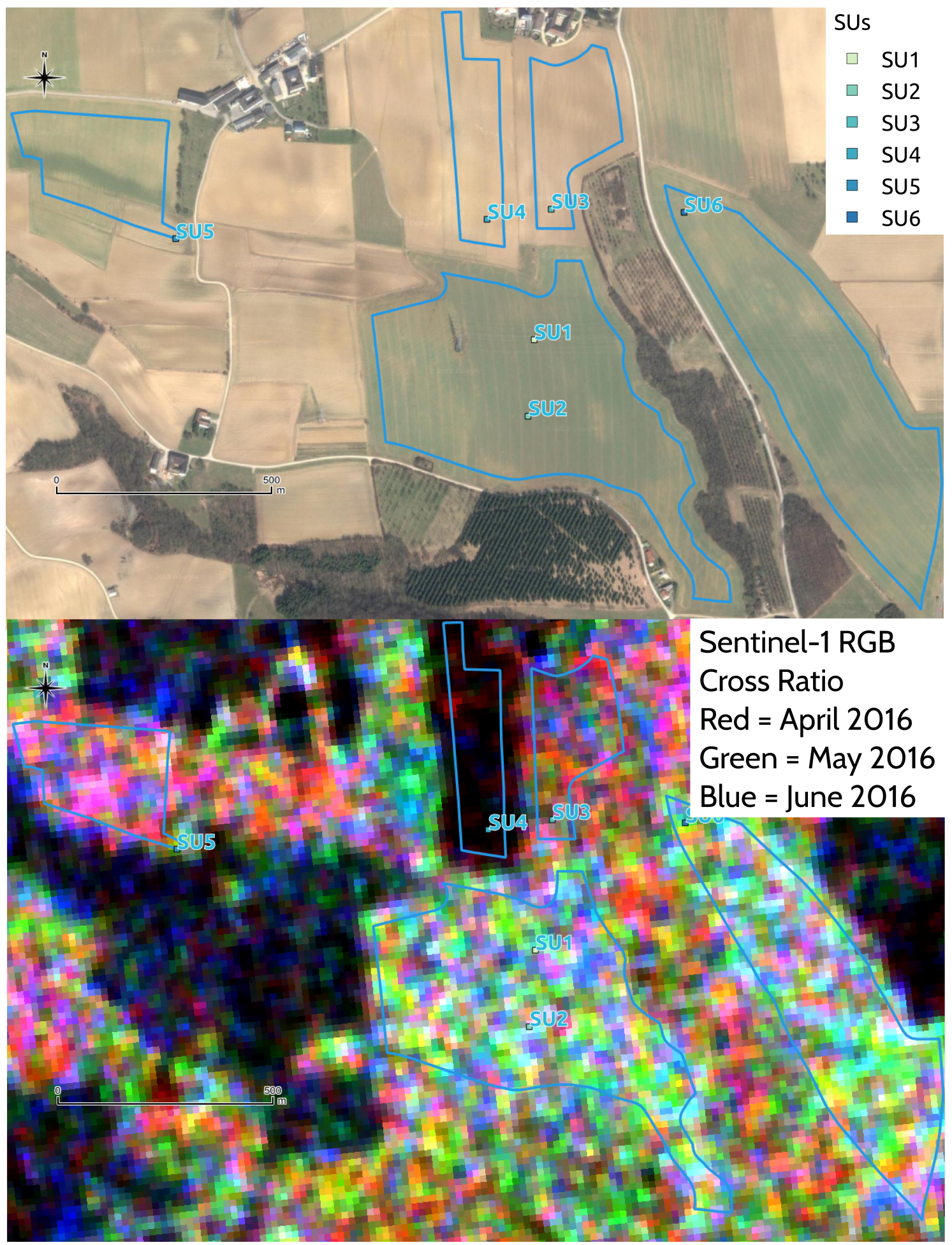

Figure 1. Map of the HOAL indicating the Sampling Unit locations (blue squares) and the area per field used to calculate Sentinel-1 indices (blue polygons). The top graph shows a Google Earth Image as the background, the lower figure depicts monthly averaged Sentinel-1 CR for the months April (Red), May (Green) and June (Blue) 2016. 
Table 1. Crop type, number of samples (NS), seeding and harvest dates (year/month/day and day of year) per year and SU. In addition, timing of phenological stages stem extension (St.), flowering (Fl.), heading (He.) and ripening (Ri.) are given in day of year for oilseed-rape (Rape) and winter cereal (Cereal) and growth stages' three leaves (V3), 12 leaves and cob development (V12), flowering (R1) and maturity (R6) are given for corn.

\begin{tabular}{|c|c|c|c|c|c|c|c|c|c|}
\hline SU & Area & Crop & NS & Seeding & Harvest & St./V3 & F1./V12 & He./R1 & Ri./R6 \\
\hline \multirow{2}{*}{1} & \multirow{2}{*}{5 ha } & Rape & 3 & '15/08/29 (241) & '16/07/23 (205) & \multirow{2}{*}{\multicolumn{2}{|c|}{$\sim 104$}} & & $\sim 130$ \\
\hline & & Cereal & 11 & '16/11/29 (334) & '17/07/19 (200) & & & $\sim 150$ & $\sim 170$ \\
\hline \multirow{2}{*}{2} & \multirow{2}{*}{6.1 ha } & Rape & 11 & '15/08/29 (241) & '16/07/23 (205) & \multirow{2}{*}{\multicolumn{2}{|c|}{$\sim 104$}} & & $\sim 130$ \\
\hline & & Cereal & 11 & '16/11/29 (334) & '17/07/19 (200) & & & $\sim 150$ & $\sim 170$ \\
\hline \multirow{2}{*}{3} & \multirow{2}{*}{$2.6 \mathrm{ha}$} & Cereal & 9 & '15/10/05 (278) & '16/07/23 (205) & \multirow{2}{*}{$\begin{array}{l}\sim 100 \\
\sim 135\end{array}$} & & $\sim 145$ & $\sim 165$ \\
\hline & & Corn & 11 & '17/04/22 (112) & '17/10/25 (298) & & $\sim 180$ & $\sim 205$ & $\sim 252$ \\
\hline \multirow{2}{*}{4} & \multirow{2}{*}{$2.3 \mathrm{ha}$} & Corn & 10 & '16/04/27 (118) & '16/09/30 (274) & \multirow{2}{*}{$\begin{array}{l}\sim 150 \\
\sim 135\end{array}$} & \multirow[t]{2}{*}{$\sim 188$} & $\sim 203$ & $\sim 253$ \\
\hline & & Cereal & 11 & '16/10/31 (305) & '17/07/19 (200) & & & $\sim 150$ & $\sim 170$ \\
\hline \multirow{2}{*}{5} & \multirow{2}{*}{3.2 ha } & Cereal & 9 & '15/10/02 (275) & '16/07/01 (183) & \multirow[t]{2}{*}{$\sim 100$} & & $\sim 130$ & $\sim 150$ \\
\hline & & Rape & 11 & '16/08/25 (238) & '17/07/19 (200) & & $\sim 100$ & & $\sim 135$ \\
\hline \multirow{2}{*}{6} & \multirow{2}{*}{9.4 ha } & Rape & 0 & '15/08/28 (240) & '16/07/20 (202) & \multirow{2}{*}{\multicolumn{2}{|c|}{$\sim 104$}} & & $\sim 130$ \\
\hline & & Cereal & 11 & '16/11/01 (306) & '17/07/19 (200) & & & $\sim 150$ & $\sim 170$ \\
\hline
\end{tabular}

\subsubsection{Soil Moisture and Precipitation}

Soil moisture is monitored continuously with the in situ soil moisture network, which is installed in the HOAL. Soil moisture and soil temperature are measured using low-current Time Domain Transmission (TDT) probes called SPADE (sceme.de GmbH i.G., Horn-Bad Meinberg, Germany). In the summer of 2013, soil moisture stations were installed at 30 locations throughout the HOAL. Per station, four sensors are horizontally installed at the following depths: $0.05,0.10,0.20$ and $0.50 \mathrm{~m}$. The network is calibrated in natural soil, by creating a test bed in the field with homogenized soil and TDT sensors and laboratory calibrated TDR sensors were installed at $0.10 \mathrm{~m}$ depth and two at $0.20 \mathrm{~m}$ depth. The four TDT sensors were calibrated with the TDR as the reference measurement of soil moisture. For this study, we used soil moisture from one station at $5 \mathrm{~cm}$, which is representative for the rest of the catchment. Precipitation is recorded every minute at four OTT Pluvio rain gauges distributed throughout the catchment. In this study, we used daily sums of precipitation, averaged for the four rain gauges.

\subsection{Sentinel-1}

Sentinel-1 is part of Europe's Copernicus programme and at the moment has two satellites in orbit, Sentinel-1A and Sentinel-1B launched in April 2014 and 2016, respectively. The Sentinel-1 satellites carry Synthetic Aperture Radars (SAR), providing backscatter at C-band $(5.405 \mathrm{GHz})$. The acquisition mode over (non-polar) land is Interferometric Wide (IW) swath mode. The SAR instruments are designed to provide co- and cross-polarized backscatter over a $250 \mathrm{~km}$ swath at a $20 \mathrm{~m}$ spatial resolution in single look. The temporal revisit time of one Sentinel-1 satellite is 12 days, and temporal coverage is 1.5-4 days over Europe using both Sentinel-1A and Sentinel-1B.

\section{Methods}

This study investigates the potential of microwave indices for crop monitoring in two ways. First, the temporal evolution of vegetation variables, soil moisture and Sentinel-1 VH and VV backscatter and CR are investigated and discussed in detail. Secondly, quantitative analyses are performed by calculating correlation statistics between backscatter data fitted to in situ observations using a linear model, exponential model and Random Forest (RF) modelling. 


\subsection{Microwave Indices from Sentinel-1}

Sentinel-1 data processed at the Earth Observation Data Centre for Water Resources monitoring $\mathrm{GmbH}$ (EODC) and TU Wien using the Sentinel Application Platform (SNAP) toolbox provided by ESA. The first step is the radiometric calibration that converts the intensity into normalized backscatter $\left(\sigma^{\circ}\right)$. This is followed by the terrain correction using Range Doppler Terrain correction with the Shuttle Radar Topography Mission digital elevation model provided with SNAP and georeferencing. The resulting $\sigma^{\circ}$ is available at a $10 \mathrm{~m}$ sampling.

To bypass incidence angle effects and other observation geometry effects, only one orbit is used, providing Sentinel-1A observations every 12 days. For every crop field that contains an $\mathrm{SU}, \sigma^{\circ}$ is averaged over the whole field in the linear domain. To rule out border effects, a $50 \mathrm{~m}$ buffer from the field borders is excluded from the calculation. The areas used and an RGB image of S1 Cross Ratio between VH and VV backscatter for April, May and June are shown in Figure 1. First, both VV and $\mathrm{VH}$ backscatter are averaged and then $\mathrm{CR}$ is calculated as VH/VV in the linear domain. As a last step, all values are converted to the logarithmic domain.

Total backscatter from a vegetated surface does not only comprise scattering from the vegetation itself. It also includes the backscatter originating from the underlying surface attenuated by the vegetation, and interaction between soil and vegetation. To simplify backscatter from vegetated surfaces, vegetation is often regarded as a cloud of randomly distributed water droplets, which are structurally held in place by dry matter. The predominant mechanism responsible for backscatter from vegetation is volume scattering. Often, cross-polarized backscatter is most indicative for these scattering mechanisms and high correlations have been found between cross-polarized backscatter at C-Band and crop condition indicators such as LAI and biomass $[12,13,22]$. Since cross-polarized backscatter increases more strongly with volume scattering than co-polarized backscatter, $C R$ increases with vegetation. By using the $C R$, the effect of soil moisture is reduced as well as soil-vegetation interaction effects [20]. However, a challenge in using cross-polarized backscatter or CR is the effect of soil roughness and vegetation structure. Soil roughness also causes depolarisation when soils are rough and have the same backscatter or $\mathrm{CR}$ values as a vegetated surface. Vegetation structure significantly impacts backscatter and, for some crops, structure can change throughout the growing season. Hence, monitoring $\mathrm{VWC}_{t}$ using SAR is complex and more research is needed quantifying the potential of SAR for crop monitoring.

\subsection{Linear and Exponential Model}

For all quantitative analyses, in situ and remote sensing observations are aggregated per crop type over the different fields and years. In situ measurements of vegetation variables were only taken when crops are present on the field and not during intercropping periods. The Sentinel-1 observations are temporally matched to the in situ measurements and analyses are thus only performed on dates when crops are present. To relate Sentinel-1 backscatter and CR to in situ observations, two models are used. First, Sentinel-1 observations are directly compared to in situ observations using a linear model. Secondly, as done by Wiseman et al. [17], an exponential model is developed, calculating the logarithm of the dependent variables. Temporal correlation coefficients $\left(\mathrm{R}^{2}\right)$ are calculated between results from the linear and exponential model results and the in situ data of $\mathrm{VWC}_{t}, \mathrm{VWC}_{l}, \mathrm{VWC}_{s}$, $\mathrm{BM}, \mathrm{LAI}$ and height. Results of the temporal correlation analyses are discussed per crop type and per model, i.e., linear or exponential.

\subsection{Random Forest Modeling}

The sensitivity of Sentinel- 1 backscatter to $\mathrm{VWC}_{t}$ is further quantified using a supervised random forest (RF) machine learning approach. RF has the advantage that it does not make any assumptions about the relation between input variables and the response variable and can identify nonlinear relationships. $\mathrm{RF}$ uses multiple regression trees that are trained on the response variable, in this study $\mathrm{VWC}_{t}$. $\mathrm{RF}$ selects a random set of input variables and data points. Four RF trees all with a maximum of 500 decision trees and 
a depth of 30 are trained using all in situ observations; a separate model per crop and a model using all data and crop type as categorical variable. As inputs, the following EO based microwave indices and products are used: Sentinel-1 VH, VV and CR. Since soil moisture could be an important indicator for $\mathrm{VWC}_{t}$, surface soil moisture from in situ observations is used as additional input variable. Two soil moisture variables are used, the soil moisture at the moment of the Sentinel-1 overpass (SSM) and antecedent soil moisture (ASSM), which represents soil moisture averaged over the previous three days.

The advantage of RF is the analysis of feature importance, quantifying the relative importance of the different variables for estimating $\mathrm{VWC}_{t}$. The variable importance quantifies the decrease in performance of the model when the variable is left out of the regressor. The Out-Of-Bag (OOB) $R^{2}$ score is calculated to assess the performance of the models. Bootstrapping is used to train the RF and the OOB $R^{2}$ score is the average $R^{2}$ calculated from the trees that do not contain a certain value for $\mathrm{VWC}_{t}$ in the respective bootstrap sample. We emphasize that due to the sample size RF is not used to predict $\mathrm{VWC}_{t}$ but as a tool to analyse the sensitivity of the different microwave indices to $\mathrm{VWC}_{t}$ and their importance to represent variability in $\mathrm{VWC}_{t}$.

\section{Results and Discussion}

\subsection{Time Series Analysis}

Two complete growing seasons have been sampled and are covered by Sentinel-1. In Austria, these two years have differed significantly from each other in terms of water availability, temperature and radiation. In addition, 2016 received more than average precipitation especially in January, February, May and June, whereas 2017 received less rainfall than average. These significantly different meteorological conditions between the years provide the opportunity to investigate the sensitivity of backscatter to vegetation dynamics under varying meteorological conditions.

\subsubsection{Oilseed-Rape}

Oilseed-rape is a broadleaf plant and has a different vegetation structure than cereals. In the HOAL, oilseed-rape is seeded at 28, 29 and 25 of August 2015 and 2016 (doy 240-241 and 238) and harvested at 23, 20 and 19 of July (doy 205, 202 and 200) for 2016 (Figure 2) and 2017 (Figure 3), respectively. As for planting, flowering and ripening also happened around the same time for both years, with flowering

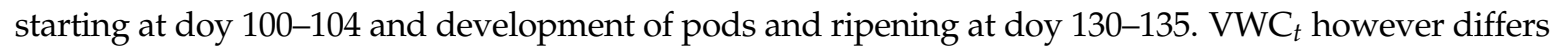
greatly between the two years, with values around $15 \mathrm{~kg} / \mathrm{m}^{2}$ in 2016 and $4 \mathrm{~kg} / \mathrm{m}^{2}$ in 2017 . This is likely caused by the different meteorological conditions between the two years. Where 2016 was an exceptionally wet year, 2017 was drier especially in May, June and July. The difference in water content originates mainly from the stem water content, which is higher in 2016 than in 2017. After a rainfall event in June 2017, water content increases with $4 \mathrm{~kg} / \mathrm{m}^{2}$ and is more comparable to 2016. This indicates rapid changes of stem water content in oilseed-rape when soil moisture is available.

For both years, the CR increases until the end of May (doy 150), apart from a peak in January 2016 and a dip in February and April 2017, which are caused by frozen soils and snow cover. VH also increases throughout the growing season. Starting around doy 110, a decrease is observed in both CR and VH backscatter, followed by a strong increase of several $\mathrm{dB}$. The small decrease coincides with the start of flowering at doy 100-104. The strong increase is observed from doy 120 to doy 132, which is at a similar time as the start of ripening. Both the decrease and strong increase related to flowering and ripening were also observed by Wiseman et al. [17] in Canada with C-band Radarsat and Veloso et al. [20] over France with Sentinel-1. The increase of VH with increasing vegetation was also observed by Macelloni et al. [14], who found that cross-polarized backscatter increased with increasing LAI over test sites in Montespertoli, Italy, and Fjardhundra, Sweden. VV backscatter varies over the year simultaneously with soil moisture, with lowest VV backscatter on doy 120 in 2016, which coincides with a drop in soil moisture. However, the decrease in soil moisture starting from doy 125 in both years is not reflected in VV backscatter. Instead, VV backscatter increases together with CR and VH backscatter. 
Even though there are clear differences in $\mathrm{VWC}_{t}$, as a result of a large difference in $\mathrm{VWC}_{s}$, and soil moisture, the CR, VV and VH are very similar for 2016 and 2017. This suggests that both VV and VH backscatter are mostly sensitive to the leaf water content but not the stem water content.

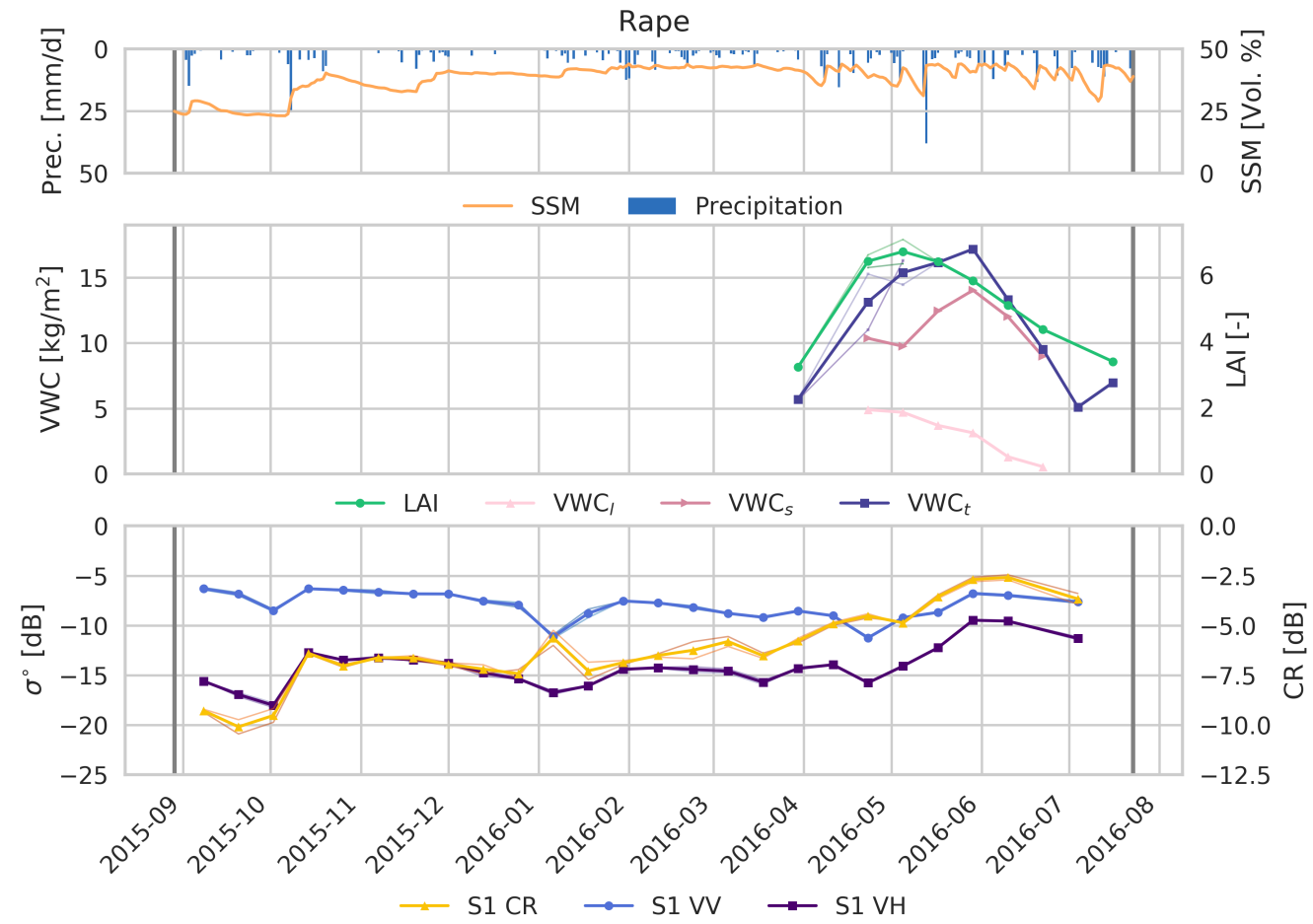

Figure 2. Time series of precipitation (blue) and soil moisture at $5 \mathrm{~cm}$ depth (orange) (top). Total VWC $\left(\mathrm{VWC}_{t}\right.$, blue), stems (VWC , pink) and leafs ( $\mathrm{VWC}_{l}$, light pink), LAI (green) (middle). S-1 VH (dark blue) and VV (light blue) and CR (yellow) (bottom). The separate fields are indicated with transparent lines. Grey vertical lines are planting and harvesting dates.
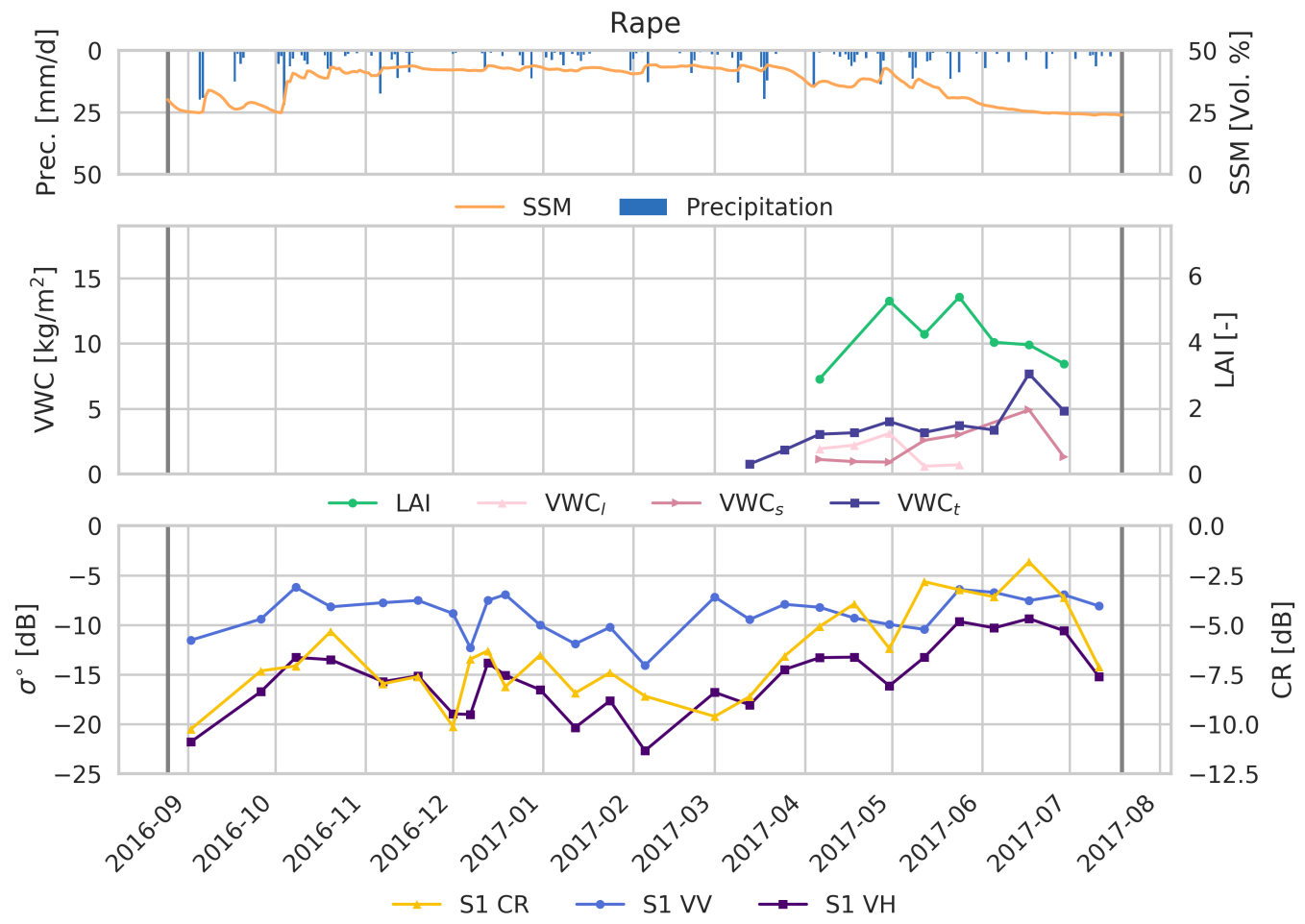

Figure 3. Time series of Sentinel-1 and in situ variables as in Figure 2 for 2017. 


\subsubsection{Corn}

Time series of in situ data and Sentinel-1 for Corn are shown in Figures 4 and 5. Like oilseed-rape, corn is a broadleaf plant. Corn is planted on 27 (doy 118) and 22 (doy 112) of April and harvested on 30 September 2016 (doy 274) and 25 October 2017 (doy 298). Around doy 135 in 2017 and doy 150 in 2016, growth stage V3 is reached, when three leaves are visible and the plant is around $20 \mathrm{~cm}$ high. Stage V10-V12, when 10-12 leafs have emerged, is reached at doy 180 in 2017 and 188 in 2016. The pollination stage

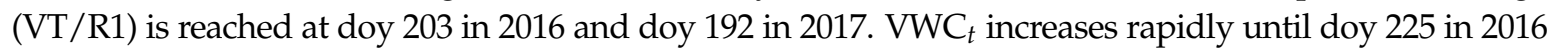
and doy 205 in 2017. In 2016, VWC $_{t}$ increases steadily and starts to decrease when soil moisture starts to decrease. In 2017, the decrease occurs earlier and $\mathrm{VWC}_{t}$ then varies until harvesting.

The CR starts to increase strongly from doy 135 in 2017 and 150 in 2016, 3-4 weeks after planting at growth stage V3 (Figures 4 and 5 and Table 1). In both years, CR increases strongly until doy 180, from $-12 \mathrm{~dB}$ to $-6 \mathrm{~dB}$. The end of the strong increase coincides with growth phase V10-V12. At this time, $\mathrm{VWC}_{t}$ also exceeds $2 \mathrm{~kg} / \mathrm{m}^{2}$ and LAI exceeds 3. Similar thresholds were found by Ferrazzoli et al. [12] and Jiao et al. [23] where backscatter and indices saturated at LAI of 2-3. In both years, CR keeps increasing slightly until doy 192 in 2017 and 205 in 203 in 2016. At this time, leaves have fully developed, dry matter has accumulated the most mass and pollination starts (VT/R1). In 2017, CR varies with $\mathrm{VWC}_{t}$, decreasing from doy 204 to 216 and then increasing to doy 240 and decreasing again during the ripening phase until harvest. This shows that, when the crop is fully grown, CR responds to small changes in $\mathrm{VWC}_{t}$. In general, VV backscatter decreases from doy 150, simultaneously with SSM. Between doy 150 and 200, VV backscatter is lower in 2017, as is soil moisture. The sensitivity of VV to soil moisture in corn can be explained by the row distance between corn. With a row spacing of $70 \mathrm{~cm}$, bare soil is still visible until a late stage, hence VV backscatter is still sensitive to soil moisture and not yet strongly attenuated by vegetation. In the same period, $\mathrm{VH}$ backscatter increases, with increasing $\mathrm{VWC}_{t}$ and with increasing LAI and closing crop cover. The same was found by Macelloni et al. [14] and Ferrazzoli et al. [12] who found an increase in C-band backscatter with increasing LAI in corn. After harvest of the corn at doy 290 in 2016 and 273 in 2017, backscatter and CR drop.

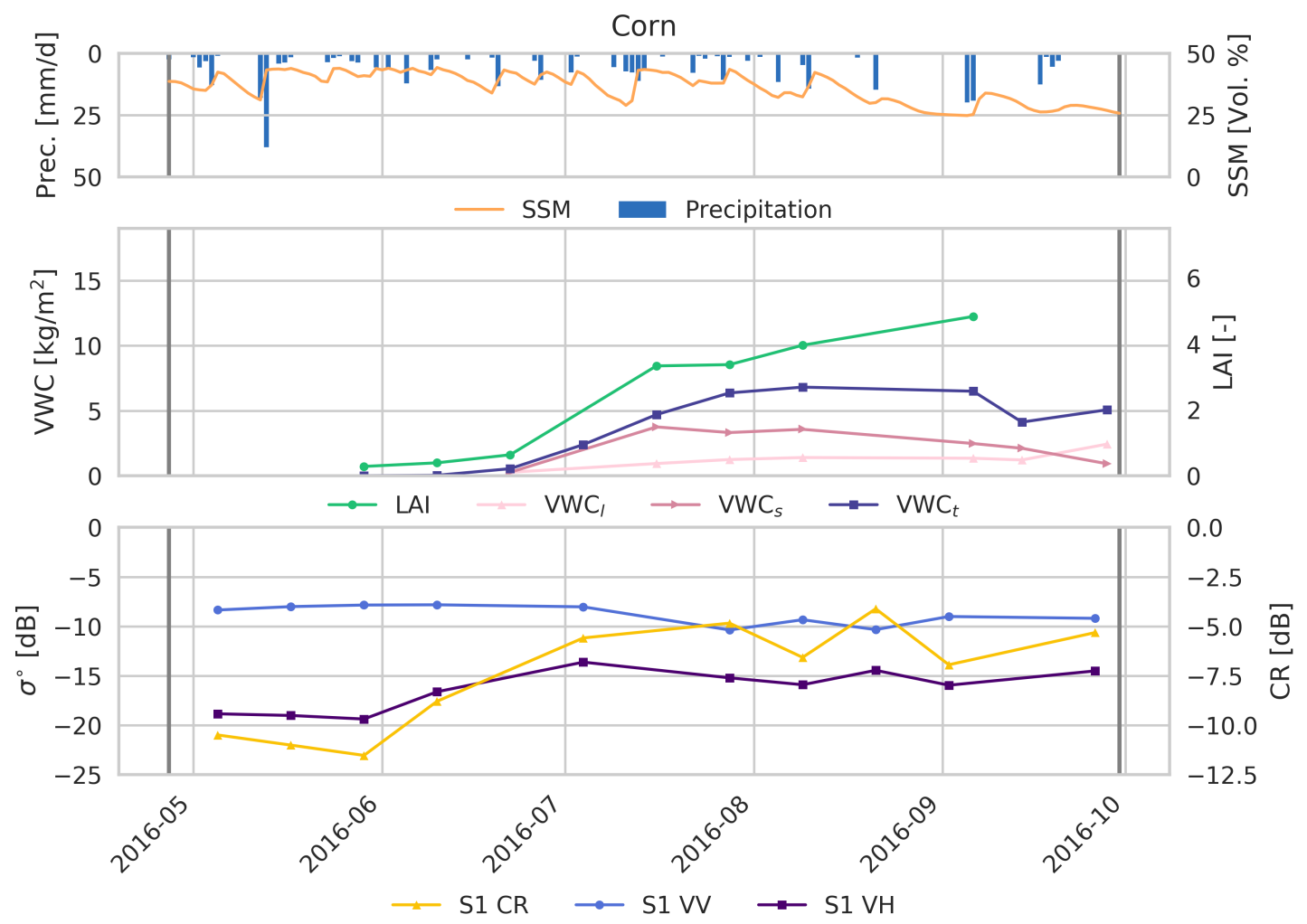

Figure 4. Time series of Sentinel-1 and in situ variables as in Figure 2 for corn 2016. 


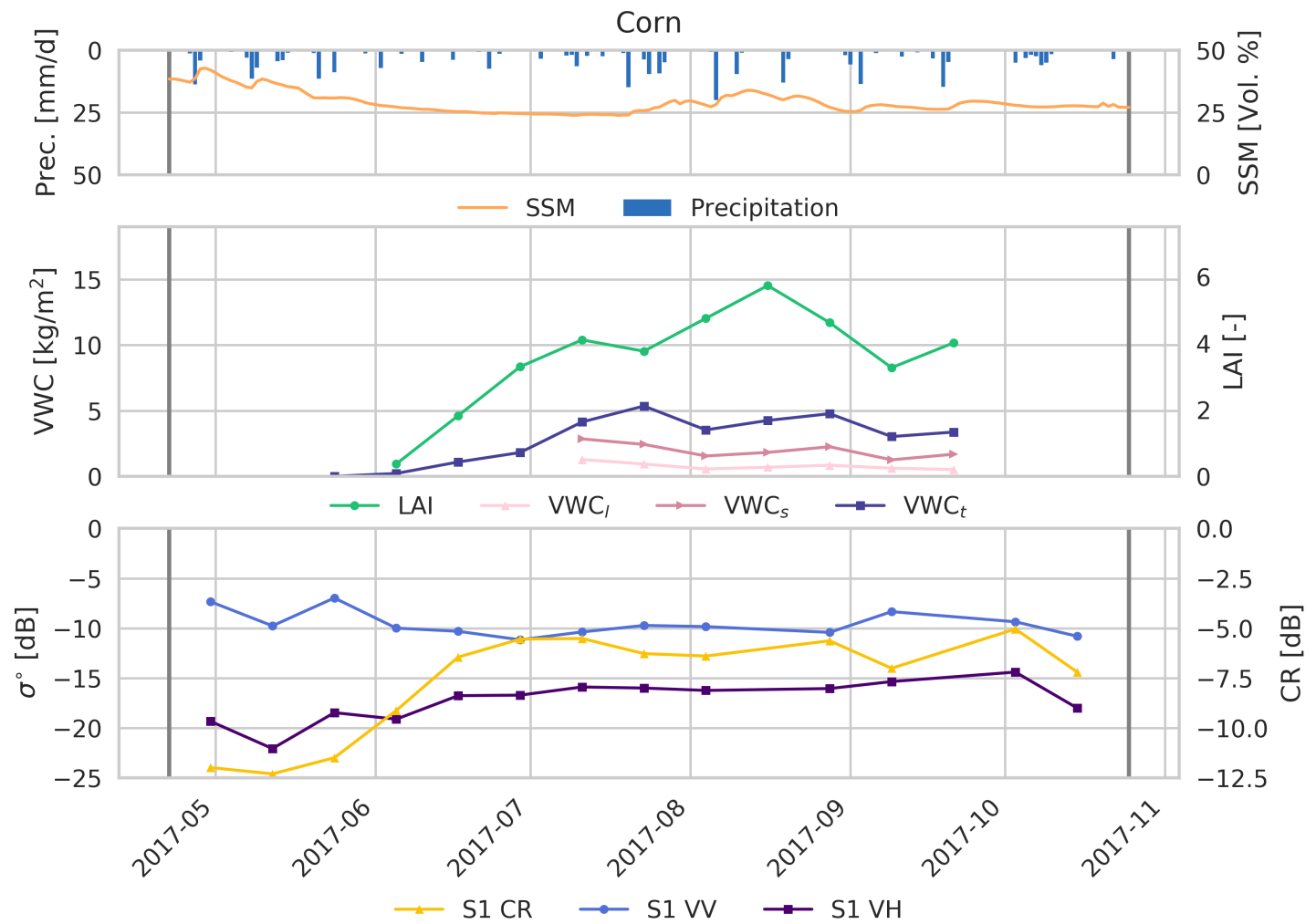

Figure 5. Time series of Sentinel-1 and in situ variables as in Figure 2 for corn 2017.

For corn, monitoring of growth stages V10-R1 is of great importance to farmers. Moisture and heat stress during the stages V10-R1 have the largest effect on final yield. In addition, management practices during these stages, e.g., application of fertilizers, can have a positive effect on yields. Hence, information of the timing of these phases and water content of the plant is pivotal and can improve farming practices.

\subsubsection{Winter Cereals}

In the HOAL, winter cereals comprise barley and wheat, both narrow-leaf crops. The growing season, phenology and structure of the two crops is very similar. The time series of the in situ data and Sentinel-1 data is shown for the growing season of 2016 and 2017 in Figures 6 and 7. Winter cereals were planted in October 2015 and November 2016 (doy 183, 200, 205). The earlier planting date and mild winter in 2016 led to an earlier start of the stem extension phase in 2016, at the middle of April (doy 100). In 2017, January and April were colder than usual and this in combination with the later planting date led to the stem extension phase to start half of May (doy 135). Heading occurred in the last weeks of May and beginning of June (doy 130-150) for both years. The shift in growth phases between 2016 and 2017 is also observed in $\mathrm{VWC}_{t}$ (Figures 6 and 7), which increases at an earlier stage in 2016 (doy 90) than in 2017 (doy 120). $\mathrm{VWC}_{t}$ keeps increasing during the grain filling period until its peak around doy 150, which is the same for both years. During the ripening stage, $\mathrm{VWC}_{t}$ decreases steadily until harvest.

Strong variations in CR in winter, especially January 2016 and February 2017, are caused by frozen soils and snow cover as was also observed in the CR for oilseed-rape. A clear steady increase in CR can be seen from doy 0 , which is during the tillering phase of winter cereals, which was also observed for winter barley by Veloso et al. [20]. The shift in growth phases between years, as was observed in in situ measurements, can also be observed in CR. CR starts to increase earlier and is overall higher in 2016 (Figure 6). This is also visible in the maxima of CR, which is at doy 102 in 2016 (Figure 6) and doy 126 in 2017 (Figure 7). The maximum in CR coincides with the start of 
the stem extension phase. During the stem extension phase, CR starts to decrease. For all fields, a dip in CR is observed around doy 150, coinciding with the maximum in $\mathrm{VWC}_{t}$ and the start of heading and flowering. During the grain fill period, CR starts to rise again and then decreases or stays constant. The changes in CR are most likely driven by phenology and large changes in vegetation structure during stem extension and heading. Similar variations related to structure were also found by Mattia et al. [18] and Satalino et al. [24]. VV backscatter decreases until the beginning of the stem extension phase of the winter cereal. Although soil moisture decreases too, small variations in soil moisture are not reflected in the VV signal. When $\mathrm{VWC}_{t}$ in the crop decreases (from day 150), a slight increase in VV backscatter can be observed even though soil moisture is still decreasing (especially in 2017). In addition, VV backscatter is lower between doy 85 and 115 in 2016 than in 2017, even though soil moisture was higher in 2016. Since vegetation water content in winter cereal was higher during this time in 2016, the lower VV backscatter in 2016 is likely caused by the increased attenuation. VH backscatter decreases during the last period of tillering. The decrease occurs earlier in 2016 than in 2017. As soon as stem extension starts, VH starts to increase again, likely as a result of volume scattering mechanisms.

The sensitivity of $C R$ to structural changes related to growth stages of winter cereals provides pivotal information on the growth stage to farmers. Winter cereals, especially wheat, are very sensitive to diseases during the flowering stage when soils are wet and temperatures are high, i.e., Fusarium a fungal disease leading to harmful mycotoxins. Infection risk can be reduced by targeted application of pesticides during flowering Chala et al. [25]. Hence, additional information on timing of flowering can assist in disease prevention and limit the use of chemicals.

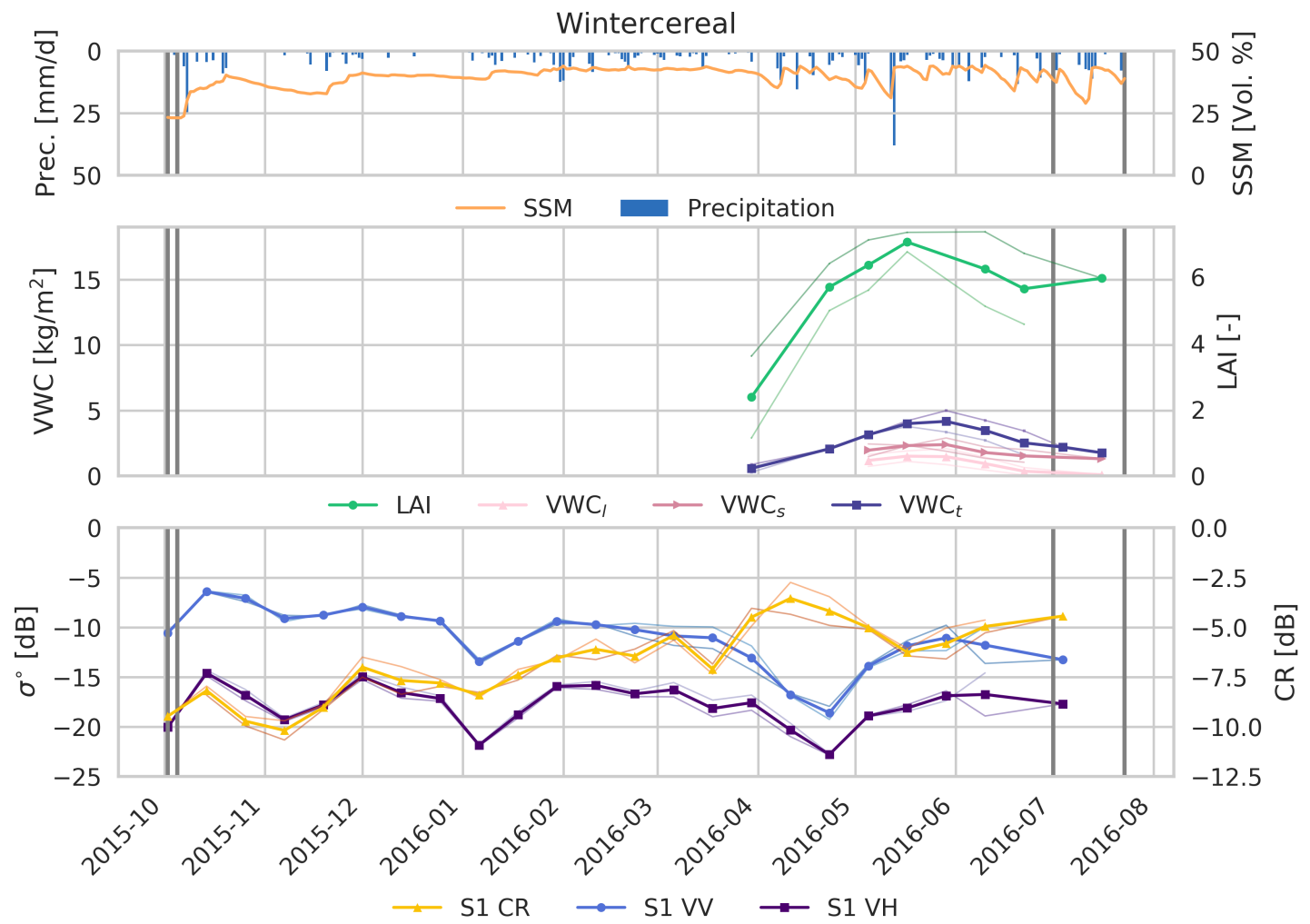

Figure 6. Time series of Sentinel-1 and in situ variables as in Figure 2 for winter cereal 2016. 


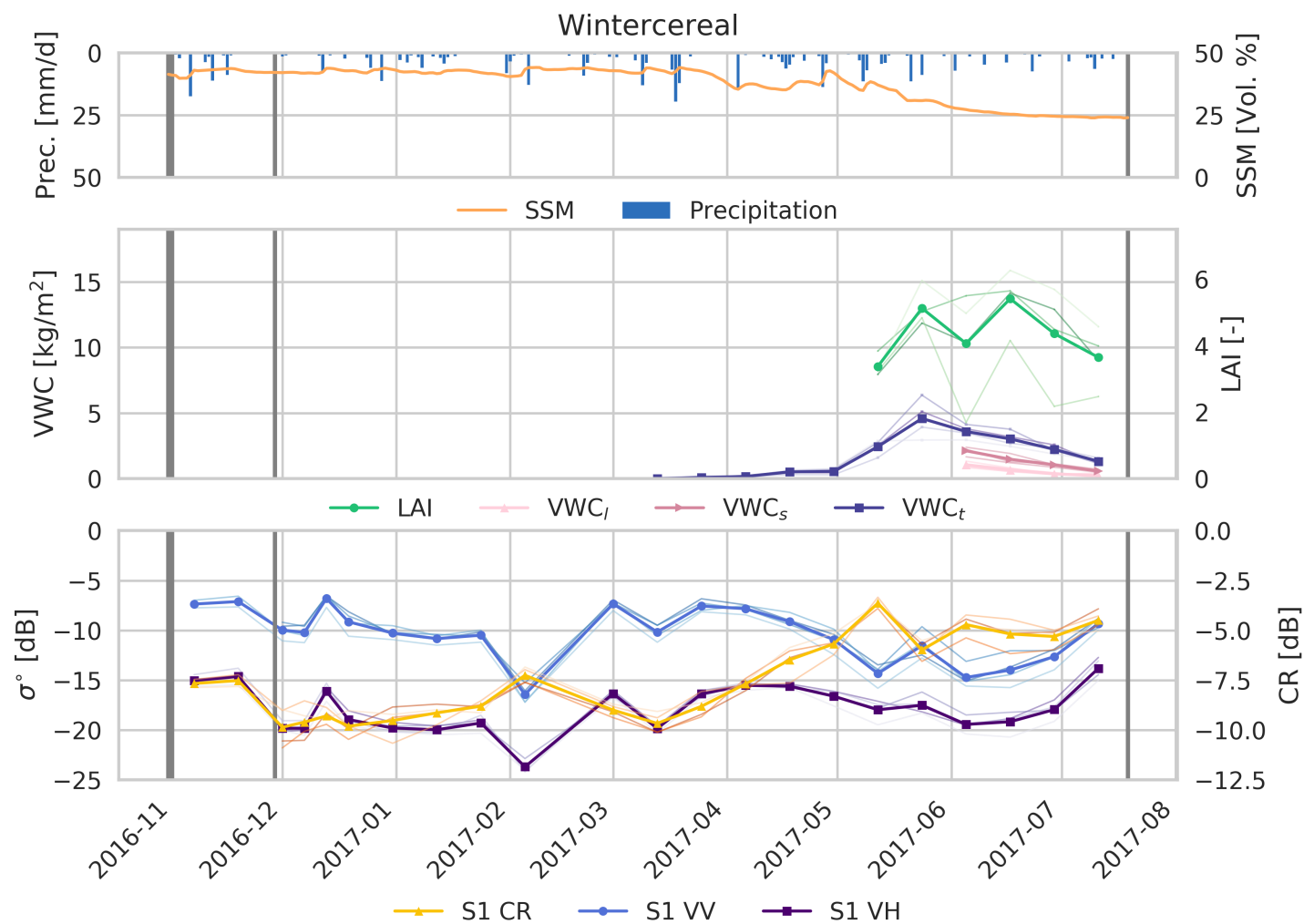

Figure 7. Time series of Sentinel-1 and in situ variables as in Figure 2 for winter cereal 2017.

\subsection{Temporal Evolution of $C R$}

Figure 8 shows the CR averaged per crop type for all fields within the HOAL for the years 2015-2017 and averaged over all years. The CR for oilseed-rape and winter cereal, which are planted in the previous autumn, starts to rise in spring (doy 70-150) and decreases in early summer (doy 170-200). CR for oilseed-rape increases steadily although some variations are visible around doy 110, which is related to flowering, as discussed in Section 4.1.1. In winter cereal, CR shows a clear dip around doy 130-150, associated with the heading as discussed in Section 4.1.3. Between years, a clear difference between the CR can be seen. In 2016, CR starts to rise earlier, from January onward. This is most likely caused by the mild winter of 2016 compared to 2015 and 2017. Corn is usually planted in April and starts to rise later in the year (doy 150-170) and decreases with harvest in autumn (doy 250-300). The CR increases continuously until the ripening stage commences. In 2017, CR in corn has its peak in June and decreases steadily until October. This could be due to the dry conditions of 2017 compared to 2015 and 2016, especially in June, July and August.

For all crops, the variability is much smaller during the growing period of the crop. Around planting time and harvest, the variability is higher since data is not masked for the planting and harvest dates per field. Due to differences in planting and harvesting dates and different field management practices, e.g., some fields are left bare while others have inter-cropping, variability of CR increases.

In the last window, the CR shows a consistent and distinct behaviour for every crop type even though different years are averaged with very different meteorological conditions and crops rotate on a yearly basis between fields. This emphasizes the sensitivity of CR to vegetation dynamics. 

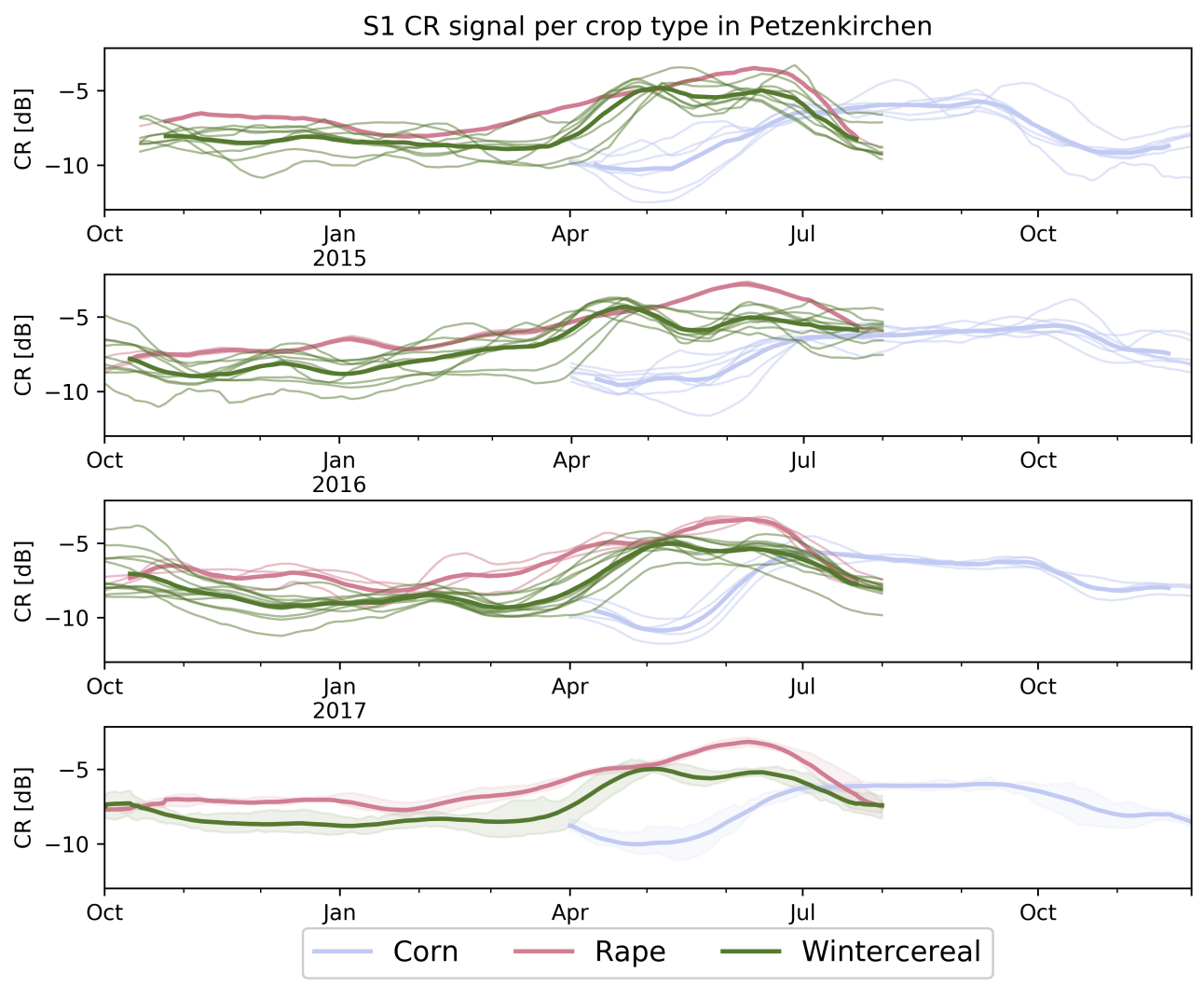

Figure 8. Cross Ratio of Sentinel-1 for different crop types per year (2015-2017) and averaged over all fields and years (lower window). The shaded areas represent the 25 th and 75 th percentile.

\subsection{Quantitative Comparison}

\subsubsection{Linear and Exponential Model Results}

The scatterplots in Figure 9 and $R^{2}$ values in Table 2 illustrate the relation between Sentinel-1 parameters and in situ measured variables. From the three microwave indices, i.e., VH, VV and CR, CR shows the highest correlation to $\mathrm{VWC}_{t}$ for all crops, with $R^{2}$ of $0.16,0.48$ and 0.22 for oilseed-rape (not-significant), corn and winter cereals, respectively, and $R^{2}=0.21$ for all crops together. CR correlates strongest to LAI in corn $\left(R^{2}=0.62\right)$, and to height for oilseed-rape $\left(R^{2}=0.51\right)$ and winter cereals $\left(R^{2}=0.50\right)$. In corn, VH backscatter is most sensitive to $\mathrm{LAI}\left(R^{2}=0.61\right)$ and $\mathrm{VWC}_{l}\left(R^{2}=0.49\right)$. This was also found by Macelloni et al. [14], who, using a simple first order radiative transfer model, showed that, at the C-band, leaves make a significant contribution to scattering in broad leaf crops. Contrary to oilseed-rape and winter cereal, in corn, the VV is moderately sensitive to soil moisture $\left(R^{2}=0.24\right)$, which was also observed in the time series evolution. This can be explained by the fact that, for the other crops, sampling started in March, when the canopy was already closed, and attenuation already affects the VV signal. The planting date in April and the row spacing of corn leaves sufficient bare soil to still observe variations in soil moisture.

The scatterplots (Figure 9) clearly indicate the nonlinear relationship between $\mathrm{CR}$ and $\mathrm{VWC}_{t}$ with a large sensitivity to low $\mathrm{VWC}_{t}$ values and saturation at high $\mathrm{VWC}_{t}$. This behaviour is observed for all vegetation variables and for all crop types. At denser vegetation, with higher $\mathrm{VWC}_{t}, \mathrm{BM}$, height and LAI, the CR appears to saturate and small uncertainties in CR can lead to large variations in $\mathrm{VWC}_{t}$. This was also seen in the time series analysis, where $\mathrm{CR}$ was more sensitive to vegetation variables especially in the early growing season. Saturation at higher crop density was also observed 
by Ferrazzoli et al. [26] for HV backscatter, Paloscia et al. [27] for VH/VV and Wiseman et al. [17] for HV backscatter and the Cloude-Pottier decomposition measure entropy. Consequently, the nonlinear relationship negatively affects the correlation of the linear model. As done by Wiseman et al. [17], an exponential model is developed, calculating the logarithm of the dependent variables. The $R^{2}$ for all crops increases with 0.42 to $R^{2}=0.63$. Values for $R^{2}$ increase dramatically for winter cereals and corn to $R^{2}=0.87$ and $R^{2}=0.63$. In winter cereals CR is still a strong indicator for height $\left(R^{2}=0.68\right)$; however, using an exponential model, CR is almost as sensitive to $\mathrm{VWC}_{t}$ as it is to height $\left(R^{2}=0.63\right)$. For oilseed-rape, $\mathrm{CR}$ is still most sensitive to height and to less extent to $\mathrm{VWC}_{t}\left(R^{2}=0.34\right)$.

The low explained variability of $\mathrm{VWC}_{t}$ by $\mathrm{CR}$ in oilseed-rape can be explained by the large difference in $\mathrm{VWC}_{t}$ between 2016 and 2017. The large difference in total $\mathrm{VWC}_{t}$ originates from the difference in stem water (Figures 2 and 3). Correlation to $\mathrm{VWC}_{s}$ is also low $\left(R^{2}=0.36\right)$. With the wavelength of C-band, it is expected that, for broad leaf crops, backscatter is more sensitive to the leaf water content. However, there is also no strong correlation between $\mathrm{VWC}_{l}$ and $\mathrm{CR}\left(R^{2}=0.31\right)$. Similar results were found by Wiseman et al. [17] and attributed the low explained variance in dry biomass to the effect of crop phenology and structure due to flowering and seeding rather than accumulation of biomass as discussed in Section 4.1.1.

\subsubsection{Random Forest Model Results}

The RF modelling is used to elucidate the potential of different microwave indices to describe variability in VWC. The RF is applied to the logarithm of the $\mathrm{VWC}_{t}$ and results of OOB $R^{2}$ score and feature importance are illustrated in Table 3.

For oilseed-rape, the OOB $R^{2}$ score of 0.31 indicates that the RF model is not able to estimate $\mathrm{VWC}_{t}$ better than a single input feature, as, for example, an exponential model using only CR. The feature importance does show that $\mathrm{CR}$ is the most important input variable to predict $\mathrm{VWC}_{t}$ with a relative importance of 0.26 . ASSM has a similar relative importance followed by SSM. This can be explained by the large difference in $\mathrm{VWC}_{t}$ between 2016 and 2017, where also soil moisture was higher in 2016 than 2017 (Figures 2 ande 3). The $\mathrm{VWC}_{t}$ in oilseed-rape is strongly related to soil moisture availability and hence soil moisture is an important predictive variable for $\mathrm{VWC}_{t}$ in oilseed-rape.

For winter cereals, the RF approach provides better results than the linear and exponential model, $R^{2}=0.81$ for RF versus $R^{2}=0.63$ for the exponential model. For winter cereals, CR varied with phenological stages and vegetation structure after the tillering phase. As such, more complex machine learning methods, which include more input variables, can better explain variability in narrow-leaf crops like winter cereals. Still, the most important variable to estimate $\mathrm{VWC}_{t}$ is $\mathrm{CR}$ with a relative importance of 0.31 , followed by ASSM and S1VV, demonstrating the potential of CR for monitoring $\mathrm{VWC}_{t}$ in winter cereal.

For corn, the exponential model performs better than the RF approach with $R^{2}=0.87$ for the exponential model and $R^{2}=0.74$ for RF. This indicates that simple exponential model between CR and $\mathrm{VWC}_{t}$ performs better for corn, and that introducing SSM and ASSM decreases the predictive performance. This is further emphasized by the variable importance for corn, where the Sentinel-1 input variables CR and VH are most important with relative importances of 0.30 and 0.25 . This can be explained by the fact that the VV backscatter for corn is sensitive to soil moisture, so that additional information on soil moisture is not of added value.

The advantage of RF is that it can also use categorical variables for building the regression model. This is done for the last RF model where all data from all crops are grouped and categorical values are given for the different crop types. The OOB $R^{2}$ score of 0.80 demonstrates the ability to describe the variability in $\mathrm{VWC}_{t}$ based on the microwave indices and soil moisture. Looking at the feature importance, it is evident that the $\mathrm{CR}$ is the variable best capturing variability in $\mathrm{VWC}_{t}$ with a relative importance of 0.35 , followed by, although at a much lower importance, VV (0.17) and VH (0.16). 

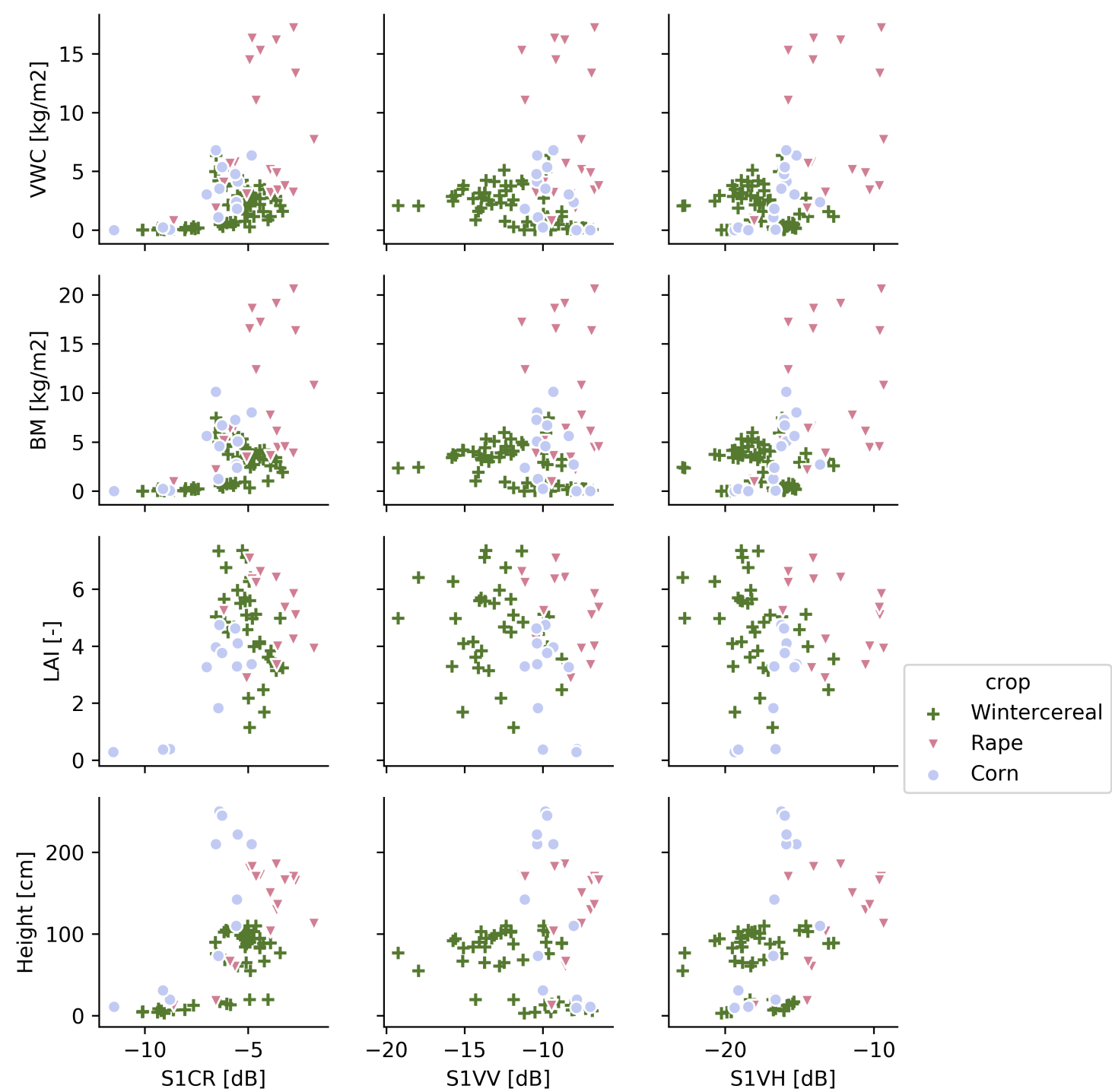

Figure 9. Scatter plot of S1 CR (left), VV (middle) and VH (right) backscatter with in situ measured vegetation variables VWC, BM and Height, and in situ measured soil moisture for the different crop types Oilseed-rape (red), Corn (purple) and winter cereal (green).

Table 2. $R^{2}$ per crop type (Oilseed-rape, Corn and Winter cereal) between Sentinel-1 CR, VH and VV for variables total VWC $\left(\mathrm{VWC}_{t}\right), \mathrm{VWC}$ from leafs $\left(\mathrm{VWC}_{l}\right), \mathrm{VWC}$ from stems $\left(\mathrm{VWC}_{s}\right)$, biomass $(\mathrm{BM})$, Leaf Area Index (LAI), plant height $(\mathrm{H})$ and soil moisture (SM) for both the linear and exponential model. In black are significant $R^{2}$ values $(p<0.05)$.

\begin{tabular}{cccccccccc}
\hline Crop & Model & Var & VWC $_{t}$ & VWC $_{l}$ & VWC $_{s}$ & $\mathbf{B M}$ & LAI & H & SM \\
\hline \multirow{6}{*}{ Oilseed-rape } & \multirow{3}{*}{ linear } & $\mathrm{CR}$ & 0.16 & 0.27 & 0.14 & 0.19 & 0.03 & 0.39 & 0.07 \\
& & $\mathrm{VH}$ & 0.03 & 0.29 & 0.06 & 0.05 & 0.03 & 0.15 & 0.16 \\
& & $\mathrm{VV}$ & 0.02 & 0.19 & 0.00 & 0.01 & 0.15 & 0.00 & 0.15 \\
\cline { 3 - 9 } & & $\mathrm{CR}$ & 0.34 & 0.31 & 0.36 & 0.34 & 0.08 & 0.51 & 0.06 \\
& \multirow{2}{*}{ exponential } & $\mathrm{VH}$ & 0.10 & 0.23 & 0.12 & 0.12 & 0.01 & 0.23 & 0.16 \\
& & $\mathrm{VV}$ & 0.01 & 0.11 & 0.00 & 0.00 & 0.13 & 0.01 & 0.16 \\
\hline
\end{tabular}


Table 2. Cont.

\begin{tabular}{cccccccccc}
\hline Crop & Model & Var & VWC $_{t}$ & VWC $_{l}$ & VWC $_{s}$ & BM & LAI & H & SM \\
\hline \multirow{5}{*}{ Corn } & \multirow{3}{*}{ linear } & CR & 0.48 & 0.16 & 0.02 & 0.42 & 0.62 & 0.55 & 0.07 \\
& & VH & 0.44 & 0.49 & 0.16 & 0.43 & 0.61 & 0.48 & 0.00 \\
& & VV & 0.15 & 0.01 & 0.23 & 0.10 & 0.19 & 0.20 & 0.24 \\
\cline { 3 - 9 } & \multirow{4}{*}{ exponential } & CR & 0.87 & 0.18 & 0.11 & 0.85 & 0.78 & 0.83 & 0.09 \\
& & VH & 0.62 & 0.35 & 0.27 & 0.63 & 0.73 & 0.61 & 0.00 \\
& & VV & 0.42 & 0.00 & 0.28 & 0.39 & 0.27 & 0.40 & 0.27 \\
\hline \multirow{3}{*}{ Winter cereal } & \multirow{3}{*}{ linear } & CR & 0.22 & 0.34 & 0.22 & 0.26 & 0.30 & 0.50 & 0.16 \\
& & VH & 0.08 & 0.14 & 0.25 & 0.04 & 0.13 & 0.00 & 0.01 \\
& & VV & 0.25 & 0.04 & 0.12 & 0.22 & 0.02 & 0.21 & 0.04 \\
\cline { 3 - 9 } & \multirow{3}{*}{ exponential } & CR & 0.63 & 0.27 & 0.19 & 0.64 & 0.22 & 0.68 & 0.15 \\
& & VH & 0.02 & 0.37 & 0.35 & 0.01 & 0.10 & 0.00 & 0.01 \\
& & VV & 0.35 & 0.19 & 0.38 & 0.32 & 0.01 & 0.28 & 0.04 \\
\hline
\end{tabular}

Table 3. OOB $R^{2}$ score and variable importance of Sentinel-1 CR, VH and VV, and surface soil moisture (SSM) and antecedent soil moisture averaged over three days prior (ASSM) from the RF modelling for $\mathrm{VWC}_{t}$ per crop type.

\begin{tabular}{|c|c|c|c|c|c|c|}
\hline Crop & OOB $R^{2}$ Score & f1 & f2 & f3 & f4 & f5 \\
\hline \multirow{2}{*}{ Oilseed-rape } & \multirow{2}{*}{0.31} & S1CR & ASSM & SSM & $\mathrm{S} 1 \mathrm{VH}$ & S1VV \\
\hline & & 0.26 & 0.26 & 0.20 & 0.15 & 0.13 \\
\hline \multirow{2}{*}{ Corn } & \multirow{2}{*}{0.74} & S1CR & $\mathrm{S} 1 \mathrm{VH}$ & ASSM & S1VV & SSM \\
\hline & & 0.30 & 0.25 & 0.18 & 0.15 & 0.12 \\
\hline \multirow{2}{*}{ Winter cereal } & \multirow{2}{*}{0.81} & S1CR & ASSM & S1VV & SSM & S1VH \\
\hline & & 0.31 & 0.20 & 0.18 & 0.16 & 0.16 \\
\hline \multirow{2}{*}{ All } & \multirow{2}{*}{0.80} & S1CR & S1VV & S1VH & ASSM & SSM \\
\hline & & 0.35 & 0.17 & 0.16 & 0.12 & 0.11 \\
\hline
\end{tabular}

\section{Conclusions}

This study assessed the sensitivity of Sentinel-1 SAR backscatter and a ratio derived thereof to vegetation dynamics. In situ data on VWC, biomass, height and LAI was collected over two growing seasons for oilseed-rape, corn and winter cereals. Using three approaches, a linear model, exponential model and random forest modelling, a quantitative analysis between SAR parameters and in situ data was performed.

Time series analysis demonstrated the sensitivity of backscatter and CR to vegetation variables such as total vegetation water content, but also the sensitivity to changes in vegetation structure. In particular, the flowering and seeding in oilseed-rape and the stem extension and head development in winter cereals affected backscatter and $\mathrm{CR}$, diminishing its sensitivity to $\mathrm{VWC}_{t}$. These observations correspond to previous studies that observed the same behaviour in the backscatter signals.

The modelling demonstrated the nonlinear relationship between $C R$ and vegetation variables. Initially, low $R^{2}$ values were found between CR and VWC for oilseed-rape and winter cereals when using a linear model. Moderate $R^{2}$ values were found for corn. Using an exponential model, CR was able to account for $34 \%, 63 \%$ and $87 \%$ of the variability in VWC in oilseed-rape, corn and winter cereal. In oilseed-rape, the $\mathrm{CR}$ cannot account for the large differences in $\mathrm{VWC}_{t}$ which were observed between the two growing seasons. In addition, at high vegetation density and high CR, CR saturates and small uncertainties in $\mathrm{CR}$ can lead to large errors in $\mathrm{VWC}_{t}$. The random forest modelling demonstrated the relative importance of $\mathrm{CR}$ for estimating $\mathrm{VWC}_{t}$ dynamics in crops, where the variable importance over all crops was 0.35 for CR. This was followed by VV and VH backscatter. It also showed that, for corn and oilseed-rape, a simple exponential model accounts better for variation in $\mathrm{VWC}_{t}$, but, for winter 
cereals, the RF model performs better when including additional soil moisture data. Since CR in winter cereals is strongly affected by changes in structure, using these additional input variables as is done in the RF approach increase the performance of the model.

The presented research demonstrates the high sensitivity of microwave indices to vegetation dynamics especially for corn and winter cereals and at low $\mathrm{VWC}_{t}$. It also provides valuable insights to ultimately predict VWC based on Earth Observation data using either simple models or machine learning approaches. Knowledge on VWC in crops can aid farmers in monitoring crop health and help decide when to irrigate and as a result could increase water use efficiency. In addition, this study confirms previous findings on changes in backscatter which are indicative for flowering and seeding of oilseed-rape. Furthermore, timing of heading and flowering in winter cereals can be observed. Since the risk of disease in oilseed-rape and winter cereals is high during flowering, information on the timing of these stages can assist in disease prevention and limit the use of chemicals. Consequently, although SAR data on itself is still affected by structural effects, valuable information can be gained on growth phases of crops. Although this study focused on a small region in Austria, it does show that information on vegetation dynamics can be obtained from Sentinel-1 observations. Further studies should focus on applying the developed method to other regions of interest. Furthermore, the added value of SAR data in combination with, for example, visible near infra-red based data could lead to improved vegetation monitoring capabilities and needs further exploration.

Author Contributions: M.V. and W.W. conceived and designed the research; M.V. performed the research, analyzed and interpreted the data and wrote the paper; B.B.-M. and C.R. interpreted the data; P.S. contributed analysis tools for the in situ validation and provided interpretation of results; I.P. collected in situ samples and provided input on analysis of results, I.T. provided input and interpretation of results on the random forest modelling. All authors have contributed to writing of the manuscript.

Funding: This research is funded by the Austrian Space Application Programme 13 (ASAP13) of the Austrian Research Promotion Agency (FFG)and the Doctoral Programme on Water Resource Systems of the Austrian Science Fund (FWF) (DK-plus W1219-N22).

Acknowledgments: Many thanks go out to Sebastian Hahn for reviewing the manuscript and contributions during discussions.

Conflicts of Interest: The authors declare no conflict of interest. The founding sponsors had no role in the design of the study; in the collection, analyses, or interpretation of data; in the writing of the manuscript, and in the decision to publish the results.

\section{References}

1. Schmidhuber, J.; Tubiello, F.N. Global food security under climate change. Proc. Natl. Acad. Sci. USA 2007, 104, 19703-19708. [CrossRef] [PubMed]

2. Godfray, H.C.J.; Beddington, J.R.; Crute, I.R.; Haddad, L.; Lawrence, D.; Muir, J.F.; Pretty, J.; Robinson, S.; Thomas, S.M.; Toulmin, C. Food security: The challenge of feeding 9 billion people. Science 2010, 327, 812-818. [CrossRef] [PubMed]

3. Steele-Dunne, S.C.; McNairn, H.; Monsivais-Huertero, A.; Judge, J.; Liu, P.W.; Papathanassiou, K. Radar remote sensing of agricultural canopies: A review. IEEE J. Sel. Top. Appl. Earth Observ. Remote Sens. 2017, 10, 2249-2273. [CrossRef]

4. Wagner, W.; Lemoine, G.; Rott, H. A method for estimating soil moisture from ERS scatterometer and soil data. Remote Sens. Environ. 1999, 70, 191-207. [CrossRef]

5. Kerr, Y.; Waldteufel, P.; Richaume, P.; Wigneron, J.P.; Ferrazzoli, P.; Mahmoodi, A.; Al Bitar, A.; Cabot, F.; Gruhier, C.; Juglea, S.; et al. The SMOS Soil Moisture Retrieval Algorithm. IEEE Trans. Geosci. Remote Sens. 2012, 50, 1384-1403. [CrossRef]

6. Parinussa, R.M.; Holmes, T.R.H.; Wanders, N.; Dorigo, W.A.; de Jeu, R.A.M. A Preliminary Study toward Consistent Soil Moisture from AMSR2. J. Hydrometeorol. 2014, 16, 932-947. [CrossRef]

7. Van der Schalie, R.; Parinussa, R.M.; Renzullo, L.J.; van Dijk, A.I.J.M.; Su, C.H.; de Jeu, R.A.M. SMOS soil moisture retrievals using the land parameter retrieval model: Evaluation over the Murrumbidgee Catchment, southeast Australia. Remote Sens. Environ. 2015, 163, 70-79. [CrossRef] 
8. Liu, Y.Y.; de Jeu, R.A.M.; McCabe, M.F.; Evans, J.P.; van Dijk, A.I.J.M. Global long-term passive microwave satellite-based retrievals of vegetation optical depth. Geophys. Res. Lett. 2011, 38. [CrossRef]

9. Jones, M.O.; Jones, L.A.; Kimball, J.S.; McDonald, K.C. Satellite passive microwave remote sensing for monitoring global land surface phenology. Remote Sens. Environ. 2011, 115, 1102-1114. [CrossRef]

10. McColl, K.A.; Entekhabi, D.; Piles, M. Uncertainty analysis of soil moisture and vegetation indices using Aquarius scatterometer observations. IEEE Trans. Geosci. Remote Sens. 2014, 52, 4259-4272. [CrossRef]

11. Vreugdenhil, M.; Dorigo, W.A.; Wagner, W.; Jeu, R.A.M.d.; Hahn, S.; Marle, M.J.E.v. Analyzing the Vegetation Parameterization in the TU-Wien ASCAT Soil Moisture Retrieval. IEEE Trans. Geosci. Remote Sens. 2016, 54, 3513-3531. [CrossRef]

12. Ferrazzoli, P.; Paloscia, S.; Pampaloni, P.; Schiavon, G.; Solimini, D.; Coppo, P. Sensitivity of microwave measurements to vegetation biomass and soil moisture content: A case study. IEEE Trans. Geosci. Remote Sens. 1992, 30, 750-756. [CrossRef]

13. Paloscia, S.; Macelloni, G.; Pampaloni, P. The relations between backscattering coefficient and biomass of narrow and wide leaf crops. In Proceedings of the 1998 IEEE International Geoscience and Remote Sensing Symposium Proceedings, Seattle, WA, USA, 6-10 July 1998; Volume 1, pp. 100-102.

14. Macelloni, G.; Paloscia, S.; Pampaloni, P.; Marliani, F.; Gai, M. The relationship between the backscattering coefficient and the biomass of narrow and broad leaf crops. IEEE Trans. Geosci. Remote Sens. 2001, 39, 873-884. [CrossRef]

15. Kim, Y.; Jackson, T.; Bindlish, R.; Lee, H.; Hong, S. Radar vegetation index for estimating the vegetation water content of rice and soybean. IEEE Geoscie. Remote Sensi. Lett. 2012, 9, 564-568.

16. Paloscia, S.; Macelloni, G.; Pampaloni, P.; Sigismondi, S. The potential of C- and L-band SAR in estimating vegetation biomass: the ERS-1 and JERS-1 experiments. IEEE Trans. Geosci. Remote Sens. 1999, 37, 2107-2110. [CrossRef]

17. Wiseman, G.; McNairn, H.; Homayouni, S.; Shang, J. RADARSAT-2 polarimetric SAR response to crop biomass for agricultural production monitoring. IEEE J. Sel. Top. Appl. Earth Observ. Remote Sens. 2014, 7, 4461-4471. [CrossRef]

18. Mattia, F.; Le Toan, T.; Picard, G.; Posa, F.I.; D’Alessio, A.; Notarnicola, C.; Gatti, A.M.; Rinaldi, M.; Satalino, G.; Pasquariello, G. Multitemporal C-band radar measurements on wheat fields. IEEE Trans. Geosci. Remote Sens. 2003, 41, 1551-1560. [CrossRef]

19. Satalino, G.; Balenzano, A.; Mattia, F.; Davidson, M.W. C-band SAR data for mapping crops dominated by surface or volume scattering. IEEE Geosci. Remote Sensi. Lett. 2014, 11, 384-388. [CrossRef]

20. Veloso, A.; Mermoz, S.; Bouvet, A.; Le Toan, T.; Planells, M.; Dejoux, J.F.; Ceschia, E. Understanding the temporal behavior of crops using Sentinel-1 and Sentinel-2-like data for agricultural applications. Remote Sens. Environ. 2017, 199, 415-426. [CrossRef]

21. Blöschl, G.; Blaschke, A.P.; Broer, M.; Bucher, C.; Carr, G.; Chen, X.; Eder, A.; Exner-Kittridge, M.; Farnleitner, A.; Flores-Orozco, A.; et al. The Hydrological Open Air Laboratory (HOAL) in Petzenkirchen: A hypothesis-driven observatory. Hydrol. Earth Syst. Sci. 2016, 20. [CrossRef]

22. McNairn, H.; Hochheim, K.; Rabe, N. Applying polarimetric radar imagery for mapping the productivity of wheat crops. Can. J. Remote Sens. 2004, 30, 517-524. [CrossRef]

23. Jiao, X.; McNairn, H.; Shang, J.; Pattey, E.; Liu, J.; Champagne, C. The sensitivity of RADARSAT-2 polarimetric SAR data to corn and soybean leaf area index. Can. J. Remote Sens. 2011, 37, 69-81. [CrossRef]

24. Satalino, G.; Mattia, F.; Le Toan, T.; Rinaldi, M. Wheat crop mapping by using ASAR AP data. IEEE Trans. Geosci. Remote Sens. 2009, 47, 527-530. [CrossRef]

25. Chala, A.; Weinert, J.; Wolf, G.A. An Integrated Approach to the Evaluation of the Efficacy of Fungicides Against Fusarium culmorum, the Cause of Head Blight of Wheat. J. Phytopathol. 2003, 151, 673-678. [CrossRef] 
26. Ferrazzoli, P.; Paloscia, S.; Pampaloni, P.; Schiavon, G.; Sigismondi, S.; Solimini, D. The potential of multifrequency polarimetric SAR in assessing agricultural and arboreous biomass. IEEE Trans. Geosci. Remote Sens. 1997, 35, 5-17. [CrossRef]

27. Paloscia, S.; Pettinato, S.; Santi, E.; Notarnicola, C.; Pasolli, L.; Reppucci, A. Soil moisture mapping using Sentinel-1 images: Algorithm and preliminary validation. Remote Sens. Environ. 2013, 134, 234-248. [CrossRef]

(c)

(C) 2018 by the authors. Licensee MDPI, Basel, Switzerland. This article is an open access article distributed under the terms and conditions of the Creative Commons Attribution (CC BY) license (http://creativecommons.org/licenses/by/4.0/). 